\section{Commentary: Management of acute uncomplicated type $B$ aortic dissection: In medio stat virtus}

\author{
Giacomo Murana, MD, $\mathrm{PhD}$, \\ Luca Di Marco, MD, $\mathrm{PhD}$, and \\ Davide Pacini, MD, PhD
}

Thoracic endovascular aortic repair (TEVAR) constitutes a paradigm shift in the treatment of Stanford type B acute aortic dissection (AD). After its introduction by Duke in 1992, it has become a landmark procedure for the treatment of aortic aneurysms. ${ }^{1}$ The first attempts to demonstrate endovascular efficacy in acute dissections were reported in 2 landmark articles in the same issue of the New England Journal of Medicine, in which we had the honor to participate. 2,3 These articles, published in 1999, strongly suggested that stent graft deployment in a dissected aortic lumen could be able to reline the true lumen, cover the entry tear, promote false lumen thrombosis, and stabilize the dissected aortic wall in a faster, safer, and more effective way than traditional open surgery. However, "all that glitters is not gold," and we all are conscious that endovascular intervention in case of acute uncomplicated type B AD remains an alternative option to medical therapy. In contrast, about $25 \%$ to $50 \%$ of patients who survive the acute "uncomplicated" phase (with an undeniable mortality of approximately $10 \%$ at 30 days) later on requires endovascular repair ${ }^{4}$ because the acute AD becomes a "complicated" disease due to pathology progression!

In this issue of the Journal, Xiang and colleagues ${ }^{4}$ summarize these concepts in a very elegant and balanced way. The authors had the ambitious idea to compare in a retrospective analysis the use of TEVAR $(n=191)$ versus medical treatment $(\mathrm{n}=166)$ in patients with acute uncomplicated type B AD. As expected also from literature, ${ }^{4}$ patients receiving

\footnotetext{
From the Cardiac Surgery Unit, Cardio-Thoraco-Vascular Department, S. Orsola Hospital, University of Bologna, Bologna, Italy.

Disclosures: Authors have nothing to disclose with regard to commercial support.

Received for publication Dec 21, 2019; accepted for publication Dec 23, 2019; available ahead of print Jan 11, 2020.

Address for reprints: Davide Pacini, MD, $\mathrm{PhD}$, Cardiac Surgery Unit, Cardio-Thoraco-Vascular Department, S. Orsola Hospital, University of Bologna, Via Massarenti 9, 40138, Bologna, Italy (E-mail: davide.pacini@unibo.it or davide.pacini@aosp.bo.it).

J Thorac Cardiovasc Surg 2021;162:37-8

$0022-5223 / \$ 36.00$

Copyright (c) 2020 by The American Association for Thoracic Surgery https://doi.org/10.1016/j.jtcvs.2019.12.085
}

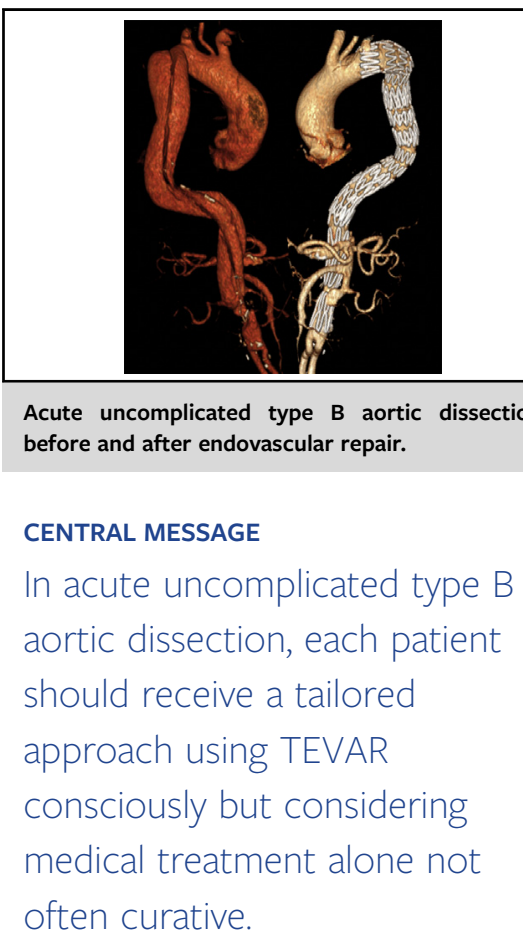

TEVAR had greater early 30-day mortality, although not statistically significant. However, those receiving best medical treatment had 3 times the risk ( $13.7 \%$ vs $5.1 \%$ at 5 years) of late adverse events (rupture and aortic enlargement) and reintervention compared with endovascular repair. In addition, patients undergoing late intervention had also a better prognosis in the TEVAR group (no deaths). In conclusion, the authors reported that "Despite more complications at the early stage, TEVAR was associated with a decreased risk of late death and with fewer late aortic ruptures compared with medical therapy in acute uncomplicated type B dissections." Unfortunately, the study has many limitations, including lack of patient selection, device availability, short follow-up time, and heterogeneity in operative strategies that only a prospective and randomized trial could be able to overcome. The ongoing Acute Dissection: Stent graft or Best medical Therapy (ADSORB) trial $^{5}$ indicated that additional TEVAR during the acute phase have no benefit in terms of mortality, prevention of aortic rupture, or dilatation, but only partial 1year results are still available.

Until now, we might observe that "in medio stat virtus" (good practice lies in the middle path). The origin of the sentence is the Nicomachean Ethics of Aristotle, which in a famous passage defines virtue: "Virtue then is a settled disposition of the mind determining the choice of actions and emotions, consisting essentially in the observance of 
the mean relative to us, this being determined by principle, that is, as the prudent man would determine it."

In the same direction, acute type $\mathrm{B} A D$ is a detrimental disease with an unpredictable way to rapidly evolve where "complicated" and "uncomplicated" are very dangerous concepts, and "virtue" should encourage managing it with caution using a tailored patient approach.

\section{References}

1. Dake MD, Miller DC, Semba CP, Mitchell RS, Walker PJ, Liddell RP. Transluminal placement of endovascular stent-grafts for the treatment of descending thoracic aortic aneurysms. N Engl J Med. 1994;331:1729-34.
2. Nienaber CA, Fattori R, Lund G, Dieckmann C, Wolf W, von Kodolitsch Y, et al. Nonsurgical reconstruction of thoracic aortic dissection by stent-graft placement. N Engl J Med. 1999;340:1539-45.

3. Dake MD, Kato N, Mitchell RS, Semba CP, Razavi MK, Shimono T, et al. Endovascular stent-graft placement for the treatment of acute aortic dissection. N Engl J Med. 1999;340:1546-52.

4. Xiang D, Kan X, Liang H, Xiong B, Liang B, Wang L, et al. Comparison of mid-term outcomes of endovascular repair and medical management in patients with acute uncomplicated type B aortic dissection. J Thorac Cardiovasc Surg. 2021;162:26-36.e1.

5. Brunkwall J, Kasprzak P, Verhoeven E, Heijmen R, Taylor P, Alric P, et al. Endovascular repair of acute uncomplicated aortic type $\mathrm{b}$ dissection promotes aortic remodelling: 1 year results of the ADSORB trial. Eur J Vasc Endovasc Surg. 2014;48:285-91.
See Article page 26

\section{Commentary: Sometimes an old dogma needs a new stent}

\author{
Kenneth R. Ziegler, MD, a and \\ Louis H. Stein, $\mathrm{MD}, \mathrm{PhD}^{\mathrm{b}}$
}

Traditional teaching dictates uncomplicated Stanford type B aortic dissection (TBAD) is best treated with optimal medical therapy (OMT). Surgery, the dictum holds, is reserved for patients at risk for catastrophic sequala of their dissection. This recommendation was driven by the high morbidity related to open repair of the thoracic aorta. Taking the most ill patients to surgery resulted in in-house mortality up to $30 \%$ for patients undergoing surgery versus around $9.0 \%$ for those undergoing stenting or medical therapy. ${ }^{1,2}$ Patients with uncomplicated type B dissections were typically treated medically and surveyed. Surgery was used if the descending aorta showed evidence of aneurysmal or false lumen enlargement.

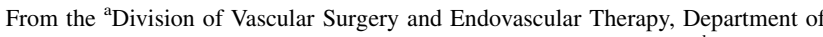
Surgery, Keck School of Medicine of USC, Los Angeles, Calif; ${ }^{\mathrm{b}}$ Division of Cardiothoracic Surgery, Department of Surgery, Albany Medical College, Albany, NY.

Disclosures: Authors have nothing to disclose with regard to commercial support.

Received for publication Dec 16, 2019; revisions received Dec 16, 2019; accepted for publication Dec 16, 2019; available ahead of print Jan 7, 2020.

Address for reprints: Louis H. Stein, MD, PhD, Division of Cardiothoracic Surgery, Albany Medical Center Surgeons Pavilion, 3rd Floor 50, New Scotland Ave, Albany, NY 12208 (E-mail: stein11@ amc.edu).

J Thorac Cardiovasc Surg 2021;162:38-9

$0022-5223 / \$ 36.00$

Copyright (c) 2020 by The American Association for Thoracic Surgery

https://doi.org/10.1016/j.jtcvs.2019.12.050
}

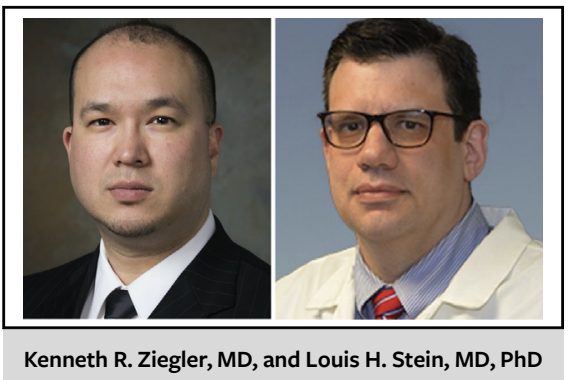

CENTRAL MESSAGE

At one time reserved as a less morbid treatment for complicated type B dissection, TEVAR may play a role in uncomplicated type $\mathrm{B}$ disease.

Over the past 2 decades, endovascular stenting established efficacy in the treatment of aortic disease, including TBAD. Thoracic endovascular aortic repair (TEVAR) first demonstrated clinical utility in the treatment of complicated TBAD. ${ }^{3}$ The INSTEAD (Investigation of Stent Grafts in Aortic Dissection Trial) study compared OMT $(\mathrm{n}=68)$ with TEVAR $(\mathrm{n}=72)$ in patients with uncomplicated TBAD. ${ }^{4}$ The survival benefit of stenting was not obvious until 5 years following presentation. ${ }^{4}$ In this edition of the Journal, Xiang and colleagues ${ }^{5}$ provide a retrospective review of a large cohort that further supports the rationale for endovascular treatment of TBAD. Their study 